\title{
Design and Analysis of 15 Level Multilevel Inverter with Reduced Number of Switches for Renewable Applications
}

\author{
Maadhushree $\mathrm{M}^{1}$, Divyani $\mathrm{J}^{2}$, Nimitha $\mathrm{M}^{3}$, Lakshmi $\mathrm{M}^{4}$, Ruma Sinha ${ }^{5}$ \\ Department of Electrical and Electronics Engineering \\ Global Academy of Technology \\ Bangalore, Karnataka, India
}

\begin{abstract}
To reduce the environmental impact, power generation using solar power plants is increasing day by day. The generated DC needs to be converted to AC for the AC loads or to connect to the grid without disturbing the grid performance. Multilevel inverters is a good option as the output voltage of a Multilevel inverter is a stepped waveform which approaches a sinusoid providing lesser harmonic distortion. As the number of levels are increased the harmonic distortion reduces but at the same time the number of switching devices and the DC voltage sources required increases, thus increasing the complexity of the system design and control. Multilevel inverter proposed in this paper uses only 7 switches to provide 15 levels of output voltage for renewable applications such as solar $P V$. As the number of switches used are less, the complexity and the control is reduced.
\end{abstract}

Keywords-Multilevel inverter; 15 level MLI; reduced number of switches; total harmonic distortion.

Abbreviations: MLI, Multievel Inverter; EMI, Electro Magnetic Interference; PV, Photo Voltaic; NPC, neutral point clamped; PWM, Pulse Width Modulation; THD, total Harmonic Distortion.

\section{INTRODUCTION}

Power generation using renewable energy resources is increasing rapidly due to the fast depleting fossil fuel and their impact on the environment. When multiple renewable generation units are interconnected and integrated with the grid, proper synchronization is an important requirement. To connect to the grid an $\mathrm{AC}$ is required which is obtained by connecting an inverter in case of solar PV system, as the generation is DC. If the output of the inverter contains harmonics the power injected in the grid pollutes the power system. Thus a proper design of inverter, with reduced harmonic distortion, is a mandate.

In recent years, multilevel inverters have gained more scope as multilevel inverters are able to give out their high operating capability, low switching losses, and higher efficiency with lower output Electromagnetic Interference (EMI). The term 'Multilevel inverter' was first introduced by Nabae et al in the year 1981 with the first concept of the Three-level Multilevel Inverter [1]. Multilevel inverter is gaining its prominence because of its ability to meet the increasing demand of high power rated applications and also the power quality associated with its reduced total harmonic distortion. Multilevel inverters have gained a number of their applications such as UPS, power grid, solar inverter, induction heating and industrial applications with highly powered instruments. Multilevel inverters are nearly able to produce a sinusoidal output-voltage waveform using fundamental frequency switching scheme. A sine wave output is more desirable since many electrical products will be engineered to work at their best with input as sine wave AC power source. In multilevel inverters, multiple voltage sources are added to obtain a stepped waveform. As the number of steps are increased, the waveform looks more close to a sinusoid, thus reducing harmonic content.

\section{MULTILEVEL INVERTER TOPOLOGIES}

Multilevel Inverters [MLI] are the ones which can give out a stepwise output waveform with the use of power electronic switches, power diodes and some DC voltage source which might be a series/parallel connected PV cells, a renewable source or a battery. Multilevel inverters not only produce low harmonic distortion but also decrease the $\mathrm{dv} / \mathrm{dt}$ stresses on the equipment [2]. In turn the Electromagnetic compatibility can also be reduced.

Three different types of topologies are available in MLIs. They are diode clamped, Flying Capacitor and Cascaded Multilevel Inverters [3]. In diode clamped MLI, a diode transfers a limited amount of voltage, thereby reducing the stress on other electrical devices [4]. The maximum output voltage is half of the input DC voltage. The diode clamped multilevel inverter was also called the neutral point clamped (NPC) inverter. Cascaded multilevel inverter topology is based on the series connection of each sub cell of the multilevel inverter. Flying capacitor was first introduced by Meynard. This topology has reduncies in inner voltage levels; in other words, two or more valid switch combinations can produce the desired output voltage waveform [5]. Cascaded H Bridge MLIs can be either symmetrical or asymmetrical type. In symmetrical cascaded $\mathrm{H}$-Bridge all the voltage sources used are of same magnitude while in asymmetrical the voltage sources used have unequal magnitudes. Advantages of asymmetrical is that a higher number of levels can be obtained with reduced number of voltage sources. Few researchers have proposed solar based MLI in different literatures [6-8].

\section{PROPOSED MULTILEVEL INVERTER}

In this paper a hybrid technology is proposed where higher numbers of levels are obtained with reduced number of switches and lesser no. of DC voltage sources. In cascaded MLI using 8 switches we can obtain 7 levels, 12 switches are required for 9 levels and so on. The proposed topology uses only 7 Mosfet switches and three DC voltage 
Sources to obtain 15 levels. In comparison with the conventional 15-level Inverter reduced number of switches used in this topology effectively reduces the switching losses and most importantly the circuit complexity. The DC voltage source magnitude is designed with binary forms of voltage such as $\mathrm{V}, 2 \mathrm{~V}$, and $4 \mathrm{~V}$ respectively. The designed topology gives out 15-level output voltages; they are $7 \mathrm{~V}$, $6 \mathrm{~V}, 5 \mathrm{~V}, 4 \mathrm{~V}, 3 \mathrm{~V}, 2 \mathrm{~V}, \mathrm{~V}, 0,-\mathrm{V},-2 \mathrm{~V},-3 \mathrm{~V},-4 \mathrm{~V},-5 \mathrm{~V},-6 \mathrm{~V},-7 \mathrm{~V}$ respectively. Depending on the output voltage requirement, $\mathrm{V}$ can be chosen appropriately. For example to obtain peak amplitude of 21 volt, the voltage sources required are 3 volt, 6 volt and 12 volt.

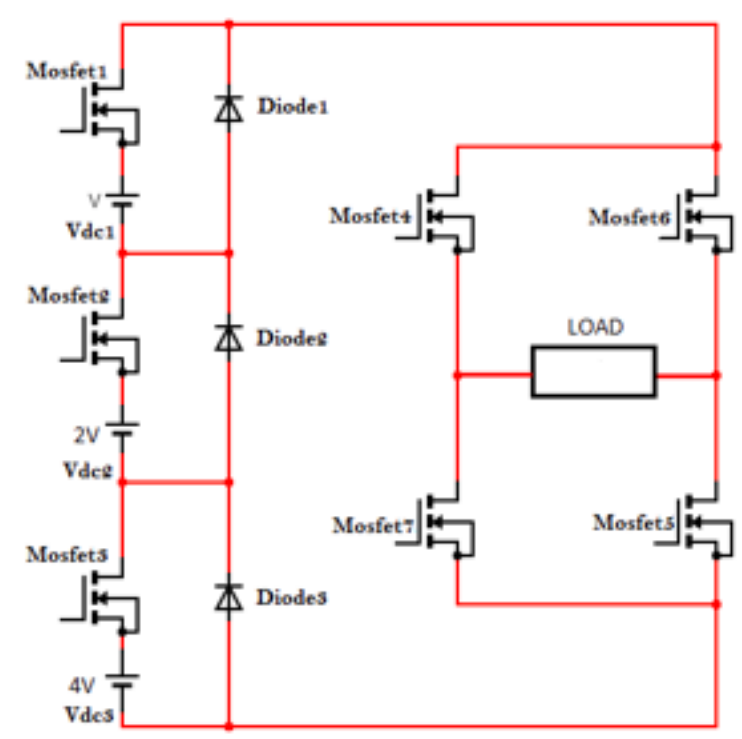

Figure 1: Circuit Diagram of the proposed 15 level MLI

The proposed fifteen level inverter, shown in figure 1, is a combination of three series connected switches with the DC sources with each switch combination having a diode connected in parallel with them.

Table 1: Switching table of the MLI

\begin{tabular}{|c|c|c|c|c|c|c|c|}
\hline Vdc & S1 & S2 & S3 & S4 & S5 & S6 & S7 \\
\hline $\mathbf{0}$ & 0 & 0 & 0 & 1 & 0 & 1 & 0 \\
\hline $\mathbf{V}$ & 1 & 0 & 0 & 1 & 1 & 0 & 0 \\
\hline $2 \mathrm{~V}$ & 0 & 1 & 0 & 1 & 1 & 0 & 0 \\
\hline $3 V$ & 1 & 1 & 0 & 1 & 1 & 0 & 0 \\
\hline $4 V$ & 0 & 0 & 1 & 1 & 1 & 0 & 0 \\
\hline $5 \mathrm{~V}$ & 1 & 0 & 1 & 1 & 1 & 0 & 0 \\
\hline $6 \mathrm{~V}$ & 0 & 1 & 1 & 1 & 1 & 0 & 0 \\
\hline $7 \mathrm{~V}$ & 1 & 1 & 1 & 1 & 1 & 0 & 0 \\
\hline$-V$ & 1 & 0 & 0 & 0 & 0 & 1 & 1 \\
\hline$-2 V$ & 0 & 1 & 0 & 0 & 0 & 1 & 1 \\
\hline$-3 V$ & 1 & 1 & 0 & 0 & 0 & 1 & 1 \\
\hline$-4 \mathrm{~V}$ & 0 & 0 & 1 & 0 & 0 & 1 & 1 \\
\hline$-5 V$ & 1 & 0 & 1 & 0 & 0 & 1 & 1 \\
\hline$-6 \mathrm{~V}$ & 0 & 1 & 1 & 0 & 0 & 1 & 1 \\
\hline$-7 \mathrm{~V}$ & 1 & 1 & 1 & 0 & 0 & 1 & 1 \\
\hline
\end{tabular}

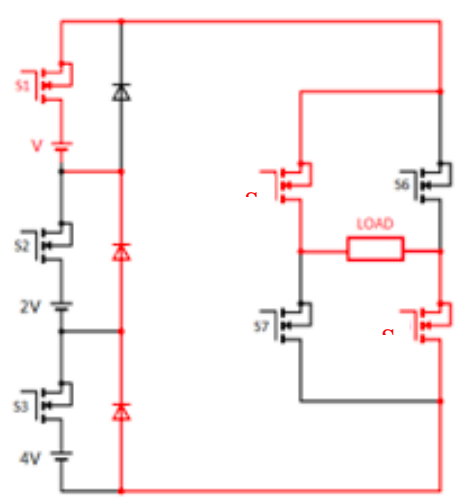

a. Mode 1 operation [output voltage V]

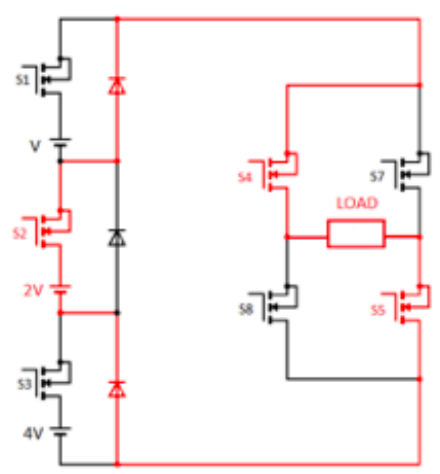

b. Mode 2 operation [output voltage 2V] 


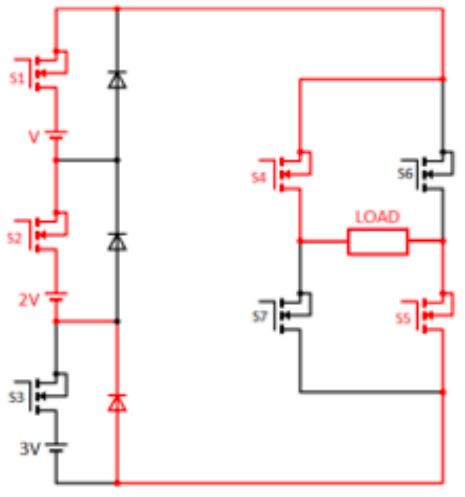

c. Mode 3 operation [output voltage 3V]

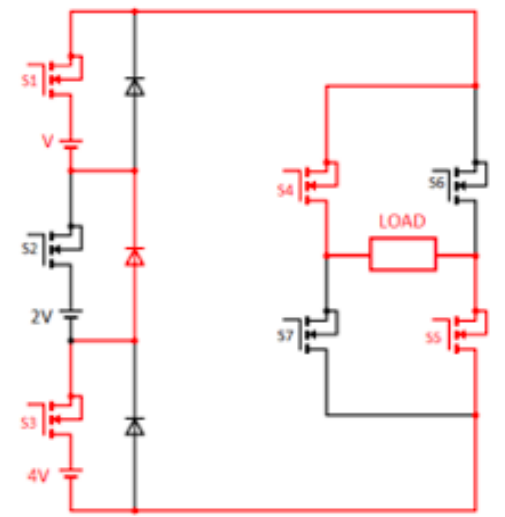

e. Mode 5 operation [output voltage 5V]

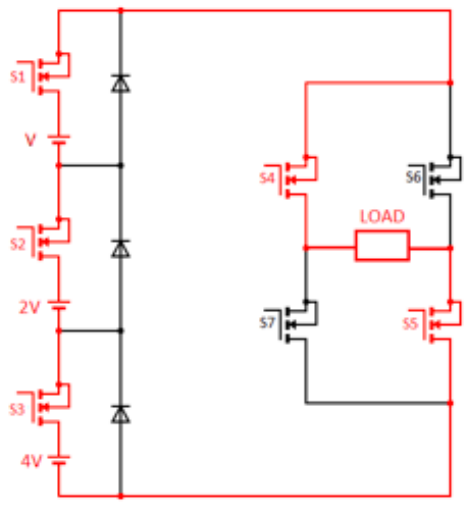

g. Mode 7operation [output voltage 7V]

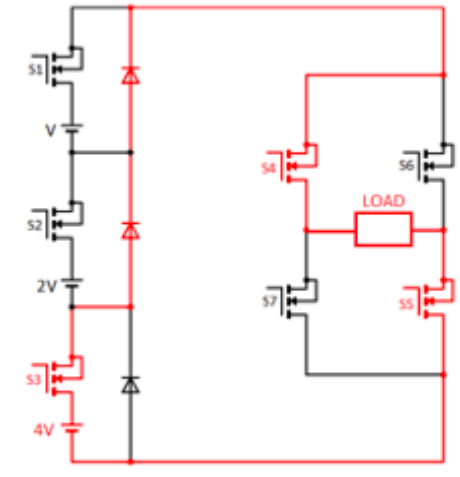

d. Mode 4 operation [output voltage 4V]

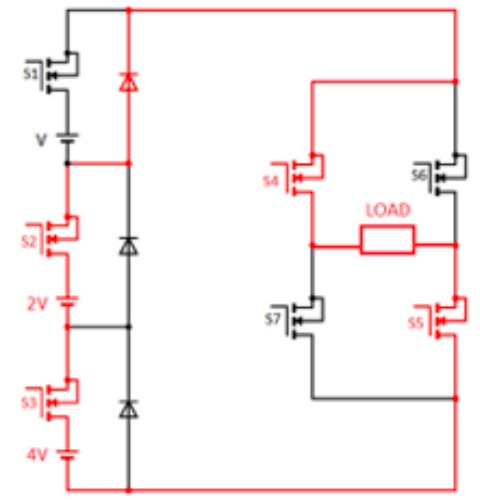

f. Mode 6 operation [output voltage 6V]

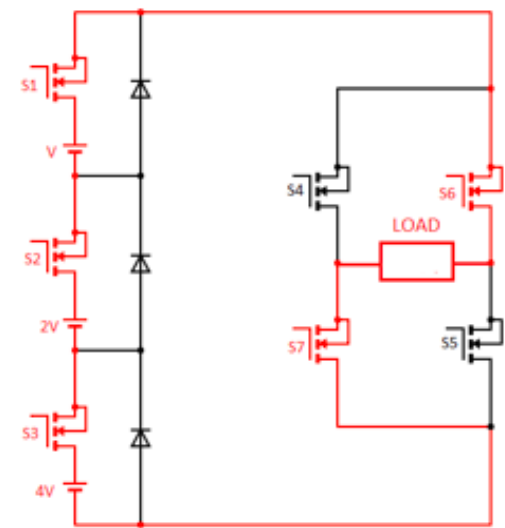

h. Mode 15 operation [output voltage -7V]

Figure 2: Current flow during different Modes of Operation of Proposed MLI

Diodes not only reduces the stress on the switch but also provides a path for the current flow when the switch is turned off. There is a cascaded $\mathrm{H}$ bridge combination that is connected with series connected switches. The pulses to the cascaded cell are given directly through the pulse generator and the pulses to the Mosfet are given as input pulses from the output of the PWM generation circuit.

\section{A. Switching sequence and mode of operation for proposed 15 level inverter}

The MLI uses 7 switches to obtain 15 levels. Switches S4, S5, s6 and S7 creates an H-bridge, while S1, S2 and S3 are the series connected switches with the DC sources. Switching table of the inverter is depicted in table 1. For zero volt output from the H bridge either S4 and S6 or S5 and S7 
should be turned on. For positive voltage S4 and S5 should be turned on and to obtain negative voltage S6 and S7 needs to be turned on.

To obtain zero volt, all the series connected switches should be turned off. For $1 \mathrm{~V}, \mathrm{~S} 1$ is turned on; for $2 \mathrm{~V}, \mathrm{~S} 2$ is turned on; for $3 \mathrm{~V}, \mathrm{~S} 1$ and $\mathrm{S} 2$ are turned on; for $4 \mathrm{~V}, \mathrm{~S} 3$ is turned on; For $5 \mathrm{~V}, \mathrm{~S} 1$ and $\mathrm{S} 3$ are turned on; for $6 \mathrm{~V}, \mathrm{~S} 2$ and $\mathrm{S} 3$ are turned on; for $7 \mathrm{~V}$, all $\mathrm{S} 1, \mathrm{~S} 2$ and $\mathrm{S} 3$ are turned on. The switch position for negative voltages remains the same for S1, S2 and S3 and but in the H-bridge switches instead of S4 and S6, S5 and S7 are to be turned on. Figure 2 shows the mode of operation in different stages and the switches that conduct during the respective mode.

\section{RESULTS AND DISCUSSION}

Figure 3 shows the overall block diagram of the system. As the asymmetrical MLI requires sources of different levels of voltages, as per requirement of the output voltage, a number of solar PV can be connected in series. Since the output voltage of solar PV depends on the solar radiation, a buck boost converter can be used to obtain a constant output voltage. To obtain 15 levels using the proposed topology three different levels of voltages are required.

Accordingly three buck boost converters are required. The system is simulated in MATLAB SIMULINK environment. The simulink model of the buck boost converter is shown in figure 4 , where the actual voltage generated by the solar PV is converted to a constant voltage matching the reference voltage. Figure 6 shows the voltage waveform with a reference voltage of $12 \mathrm{~V}$. The simulink model of 15 level inverter is presented in figure 5 and the output voltage waveform is shown in figure 7. Depending on the output voltage requirement the magnitude of the DC voltage sources can be chosen.

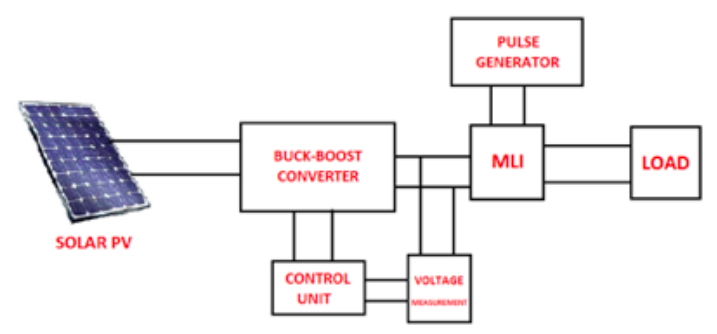

Figure 3: Block Diagram of Overall System

The simulation is conducted with $48 \mathrm{~V}, 96 \mathrm{~V}, 192 \mathrm{~V}$ DC sources to obtain $325 \mathrm{~V}$ peak amplitude which gives $230 \mathrm{~V}$ RMS output.

Figure 8 shows the FFT analysis where we can see the Total Harmonic Distortion is $4.7 \%$ which is within the acceptable limit as per IEEE 519 standard.

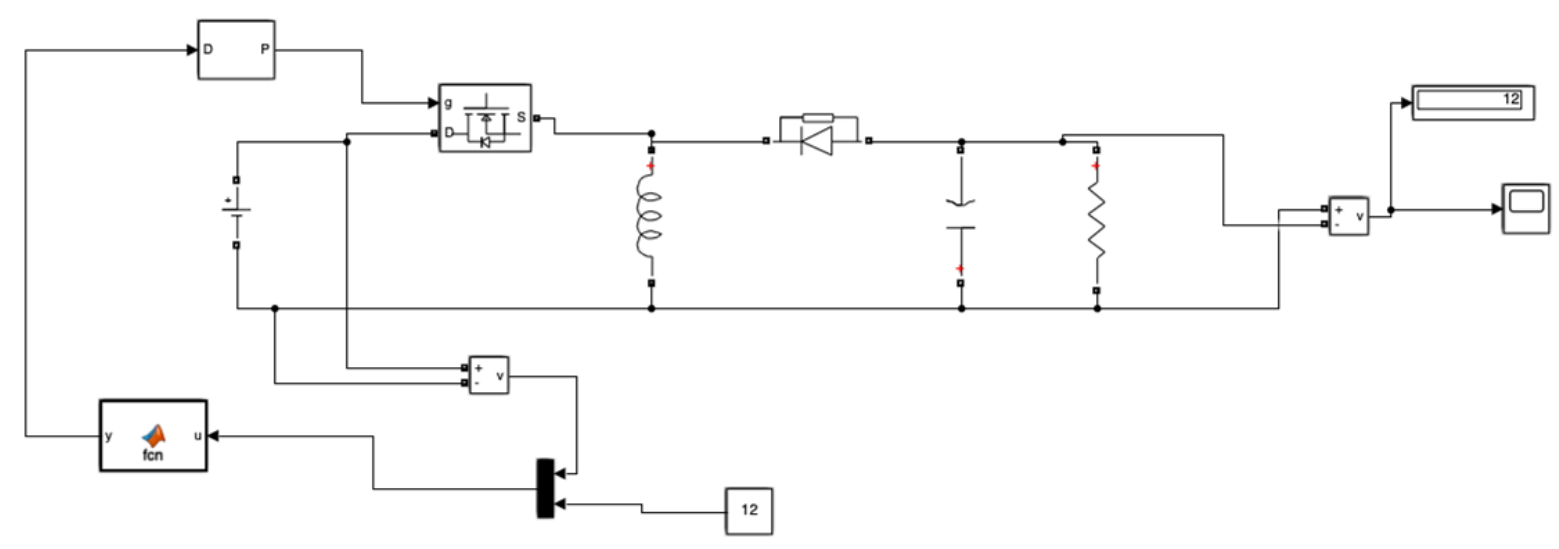

Figure 4: Simulink model of BuckBoost converter 


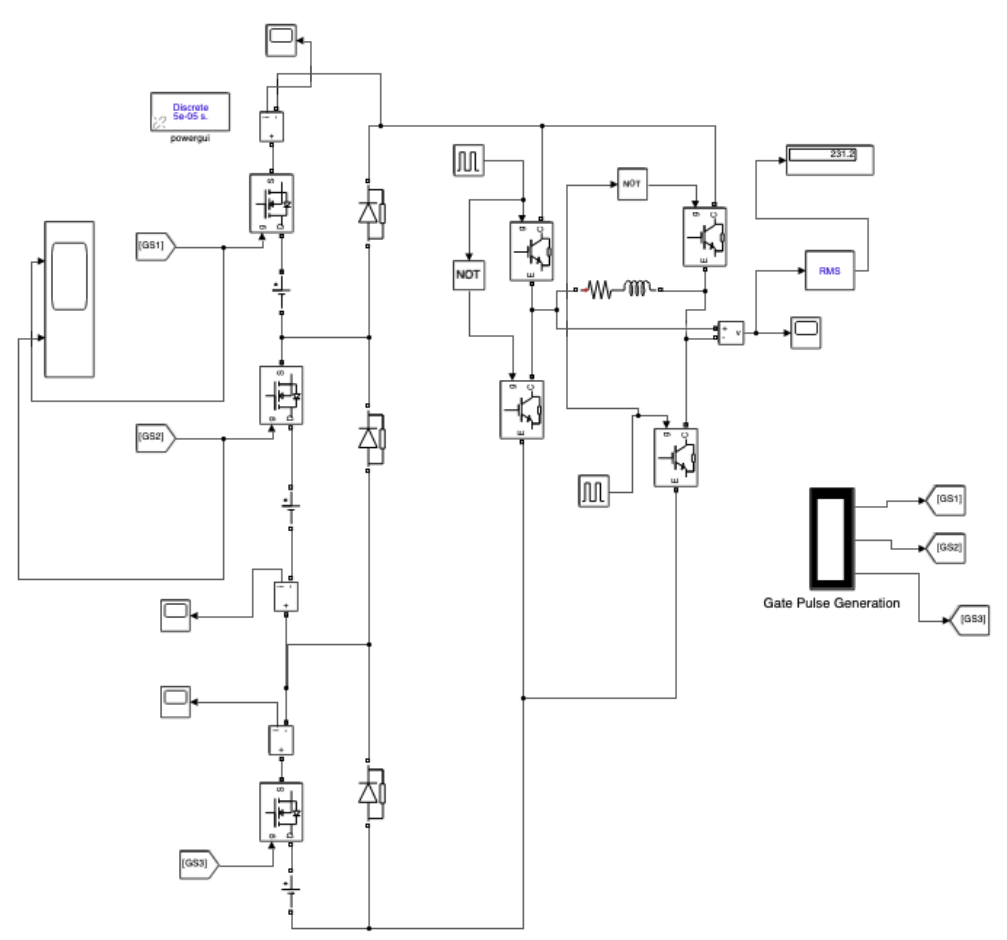

Figure 5: Simulink Model of 15 level Inverter

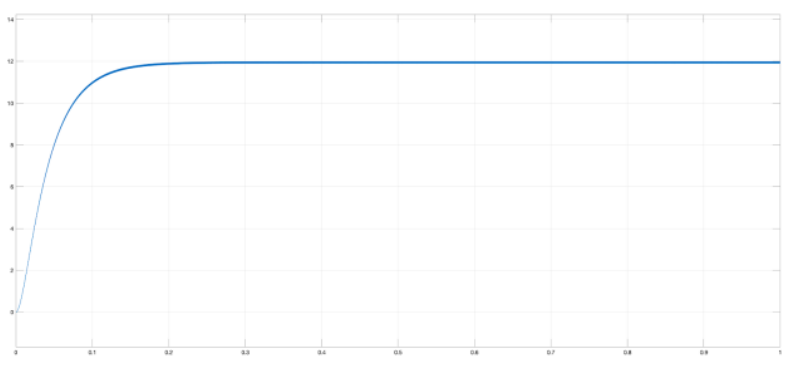

Figure 6: Output waveform of Buck-Boost Converter

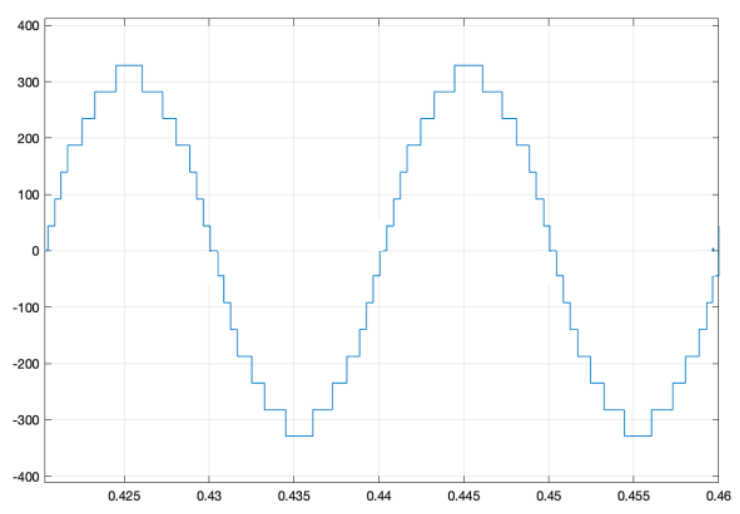

Figure 7: Output voltage Waveform of MLI

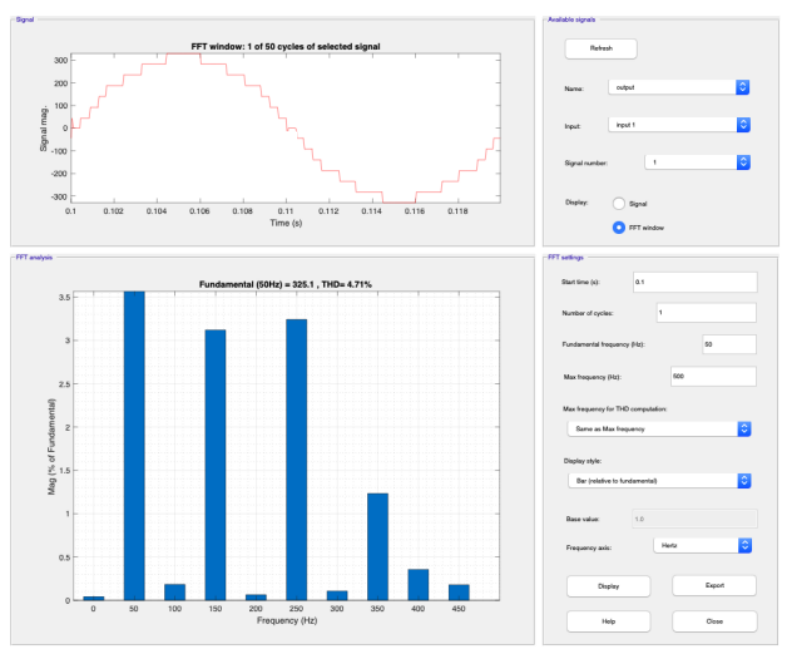

Figure 8: FFT analysis of 15 level inverter's output voltage

\section{CONCLUSION}

A multilevel inverter with 15 levels is proposed with a reduced number of switching devices. Only 7 switches are used in the proposed system, while 24 switches are required for normal cascaded MLI with 15 levels. Asymmetrical configuration helps in obtaining higher levels with less number of voltage sources. The THD in the output voltage of this 15 level MLI could be brought to $4.71 \%$ which is within the acceptable limit. 


\section{FUTURE SCOPE}

The proposed multilevel inverter can be used as a drive for solar powered applications. A closed loop control can be developed using intelligent algorithms to optimize the switching angle. The hardware implementation of the proposed work gains more importance for its future scope. Also, the designing and implementation of further levels may reduce the THD to a more lesser values and thereby decreasing and overcoming all the existing problems of the present agenda.

\section{REFERENCES}

[1] A. Nabae, I. Takahashi, H. Akagi, "A New Neutral-Point-Clamped PWM Inverter, " IEEE Transactions on Industry Applications, vol. 17. No. 5, pp.518-523, Sept. 1981.

[2] A. Krishna R and L. P. Suresh, "A brief review on multi level inverter topologies," 2016 International Conference on Circuit, Power and Computing Technologies (ICCPCT), Nagercoil, 2016, pp. 1-6, doi: 10.1109/ICCPCT.2016.7530373.
[3] Krishna Kumar Gupta, Pallavee Bhatnagar, "Conventional and emerging topologies and their control”, Academic Press, Book, 2018. ISBN 9780128124482.

[4] Xiaoming Yuan and I. Barbi, "Fundamentals of a new diode clamping multilevel inverter," in IEEE Transactions on Power Electronics, vol. 15, no. 4, pp. 711-718, July 2000, doi: 10.1109/63.849041.

[5] A. Gaikwad and P. A. Arbune, "Study of cascaded H-Bridge multilevel inverter," 2016 International Conference on Automatic Control and Dynamic Optimization Techniques (ICACDOT), Pune, 2016, pp. 179-182, doi: 10.1109/ICACDOT.2016.7877574.

[6] Ran He, Mehdi Narimani, "Modeling and Analysis of New Multilevel Inverter for Solar Photovoltaic Power Plant", International Journal of Photoenergy, Volume 2016, Article ID 4063167.

[7] Dilip1, Dr J Satheesh kumar, "Design and Development of Multilevel Inverter for Solar Power Generation", International Journal of Engineering Science and Innovative Technology (IJESIT), Volume 5, Issue 3, May 2016.

[8] Venkatachalam Kumar Chinnaiyan, JovithaJerome, J.Karpagam, “An experimental investigation on a multilevel inverter for solar energy applications", International Journal of Electrical Power \& Energy Systems, Volume 47, May 2013, Pages 157-16. 